\title{
BORGES Y CERVANTES. DON QUIJOTE Y ALONSO QUIJANO
}

En el prólogo de El oro de los tigres, se lee, entre otras cosas interesantes, que "para un verdadero poeta, cada momento de la vida, cada hecho, debería ser poético, ya que profundamente lo es. Que yo sepa, nadie ha alcanzado hasta hoy esa alta vigilia". Termina el breve cuan sustancioso prólogo con estas palabras: "En cuanto a las influencias que se advertirán en este volumen [...] en primer término, los escritores que prefiero - he nombrado ya a Robert Browning-; luego, los que he leído y repito; luego, los que nunca he leído pero que están en mí. Un idioma es una tradición, un modo de sentir la realidad, no un arbitrario repertorio de símbolos"'1.

Bien se sabe la permanente admiración de Borges por Cervantes, desde que en la niñez leyó el Quijote hasta' su muerte. Su cervantismo no se fundaba en la curiosidad por saber si su lengua se adecuaba a ciertos cánones filológicos, consuetudinarios o científicos. Le atraía más la lengua viva y auténtica del escritor que se había propuesto contar cosas y que lo hizo con maestría. Era un poeta que supo hallar el misterio poético en las cosas simples, en los sentimientos pero sin sensiblerías, en las virtudes pero sin moralina, en el ingenio agudo pero sin ostentación. Borges, por ejemplo, no se preocupó nunca por averiguar si don Quijote respondía a tal o cual modelo vivo. Le bastaba con la obra, rico testimonio de singular hondura. Después de leer el verso y la prosa borgeanos alusivos a Cervantes, se concluye que lo consideró entre los poetas de "alta vigilia". Cualquier lector del escritor argentino puede observar su admiración ante la obra de Cervantes - en especial el Quijote - por la poesía que sugiere

1 Jorge Luis Borges, El oro de los tigres (1972), Obras completas, Emecé, Buenos Aires, 1974, p. 1081.

NRFH, XL (1992), núm. 2, 1047-1056 
y de ella mana, que produce una conmovedora emoción estéti. ca y afectiva. Su cervantismo es fundamentalmente admiraciór por la obra del alcalaíno que es belleza y emoción de las cosas por su prosa, basada en imágenes extraídas de sutiles relacione: descubiertas por la imaginación; y por el lenguaje, a la vez suges tivo y musical.

En El oro de los tigres, como en tantos otros volúmenes, unc de los escritores siempre presentes es Cervantes. Porque es unc de los que prefiere, uno de los que ha leído y repite y, por fin uno de los que están en él. El castellano, antes que una suma d autores o un catálogo de libros, "es una tradición, un modo d sentir la realidad, no un arbitrario repertorio de símbolos". As lo dijo en 1972. Muchos años antes, con emoción exhortativa convincente, en 1927, afirmaba lo mismo, de otra manera: "Di gan el pecho y la imaginación lo que en ellos hay, que no otr astucia filológica se precisa"2.

El poema que nos sirve de punto de partida dice así:

\section{Sueña Alonso Quijano}

El hombre se despierta de un incierto

Sueño de alfanjes y de campo llano

$\mathrm{Y}$ se toca la barba con la mano

Y se pregunta si está herido o muerto.

¿No lo perseguirán los hechiceros

Que han jurado su mal bajo la luna?

Nada. Apenas el frío. Apenas una

Dolencia de sus años postrimeros.

El hidalgo fue un sueño de Cervantes

Y don Quijote un sueño del hidalgo.

El doble sueño los confunde y algo

Está pasando que pasó mucho antes.

Quijano duerme y sueña. Una batalla:

Los mares de Lepanto y la metralla.

Quizá convenga recordar que este poema vuelve a ser incl do por Borges, tres años después de El oro de los tigres, en otro bro que, con el título de La rosa profunda, publica en 1975. I creemos que se trate de un olvido o una simple reiteración. $\mathbf{P}$ el contrario, nos parece que se trata más bien de una preferenı por el tema que desea destacar. Creo también que, como él lo '

${ }^{2}$ Jorge Luis Borges, El idioma de los argentinos, Del Giudice Editor Buenos Aires, 1952, p. 33. 
ce en el prólogo de este segundo libro, "La misión del poeta será restituir a la palabra, siquiera de un modo parcial, su primitiva y ahora oculta virtud. Dos deberes tendría todo verso: comunicar un hecho preciso y tocarnos físicamente, como la cercanía del mar"'3. Tal es su afecto por Cervantes, por el Quijote, por "el doble sueño", que le place decirlo poéticamente y reiterarlo. Es uno de los pensamientos obsesivos de toda una vida de lector y escritor, expresado y repetido en numerosas ocasiones, que ha hallado el verso conveniente que nos informa de un hecho conmovedor y preciso y que nos toca con su invisible mano o profundo destello. Se trata de la palabra poética reveladora que el poeta, consciente del hecho, ama y reitera.

El fin está cercano o por la tristeza ocasionada por la derrota sufrida en manos del Caballero de la Blanca Luna o por singular disposición del cielo. Enfermo don Quijote gravemente y conocida la recomendación del médico de que "por sí o por no, atendiese a la salud de su alma, porque la del cuerpo corría peligro', el diagnóstico fue tomado serenamente por el protagonista y llorosamente por los circunstantes. De todios modos, este ir terminando el camino de la vida parecía natural. Menos natural y hasta asombroso pareció el despertar sano o, lo que es lo mismo, cuerdo tras su sueño de muchas horas. La confesión que le hace a la sobrina es, más que cuerda, sabia:

- Las misericordias - respondió don Quijote-, sobrina, son las que en este instante ha usado Dios conmigo, a quien, como dije, no las impiden mis pecados. Yo tengo juicio ya, libre y claro, sin las sombras caliginosas de la ignorancia, que sobre él me pusieron mi amarga y continua leyenda de los detestables libros de las caballerías. Ya conozco sus disparates y sus embelecos, y no me pesa sino que este desengaño ha llegado tan tarde, que no me deja tiempo para hacer alguna recompensa, leyendo otros que sean luz del alma. Yo me siento, sobrina, a punto de muerte; querría hacerla de tal modo, que diese a entender que no había sido mi vida tan mala, que dejase renombre de loco; que puesto que lo he sido, no querría confirmar esta verdad en mi muerte ${ }^{4}$.

${ }^{3}$ Jorge Luis Borges, La rosa profunda (1975), Obras completas, Emecé, Buenos Aires, 1989, t. 2, p. 77.

${ }^{4}$ Miguel de Cervantes Saavedra, Don Quijote de la Mancha, ed., est. y notas de Juan Bautista Avalle-Arce, Alhambra, Madrid, 1979, t. 2, cap. 74. Citaremos por esta edición. 
Es el protagonista que se reconoce cuerdo tras sus locuras, que culpa a sus abundantes lecturas de libros de caballerías de su lamentable condición pasada, el que, por fin y bondad de Dios, ha recobrado su juicio respecto de la tenebrosa ignorancia. Quisiera pagar sus pecados con nuevas lecturas pero ahora de libros píos y edificantes. En el momento final quiere obrar juiciosamente para hacer olvidar su pasado de mentecato. El momento de la muerte es cosa seria. Es el nuevo amanecer de don Alonso Quijano el Bueno, la resurrección, si se quiere, de aquel personaje del primer capítulo de la primera parte, que aparece para enloquecer muy luego y de quien el autor dice, socarronamente, no saber muy bien su nombre: ¿Quijada, Quesada o Quejana?

El caballero, en la primera parte, muere fiel a su locura, sin renunciar a su vida aventurera. Del preciso momento de su muerte nada sabemos, simplemente nos encontramos con unos epitafios y elogios de los académicos de Argamasilla. Recorde. mos que en el famoso escrutinio de la librería, Cervantes, a tra. vés del cura y con indisimulada sorna, refiriéndose a Tirante $e$ Blanco - al que llama "el mejor libro del mundo" - afirma "aquí comen los caballeros, y duermen y mueren en sus camas y hacen testamento antes de su muerte..." (I, 6) ${ }^{5}$. El autor cui dó mucho que don Quijote no le imitara para así morir en su ley Mientras que en la Segunda parte, don Quijote muere en su ca ma, llama al cura y al escribano, es decir, recibe los sacramento y testa; y vitupera "todas las historias profanas del andante caba llería". Dice "profanas". Lo profano no merece la reverenci debida a las cosas sagradas, es sinónimo de libertino y hasta d deshonesto e ignorante, sin autoridad en una materia dada.

En otra ocasión, Borges recuerda un romance de Queved "en el cual se menciona al Quijote"'6; "documento de la triste ir comprensión del Quijote en su propio siglo" acota Raimund Lida. Pues bien, este romance, Testamento de don Quijote, term na así:

${ }^{5}$ Creemos que el elogio del libro es sincero, no así esto de dormir y m rir los caballeros en sus camas, por ejemplo. Hago la aclaración porque, leíc el párrafo entero donde se inserta tal aseveración, el sentido no aparece cla. a primera vista y se ha llegado a opinar reiteradamente sobre la oscuridad d pasaje.

6Véase "La pasión literaria", en Diálogos, ed. María Esther Vázque Buenos Aires, 1978. [Este diálogo se publicó primeramente en La Nación, Bu nos Aires, 13 de febrero de 1977). 
En esto la Extremaunción

asomó ya por la puerta;

pero él, que vio al sacerdote

con sobrepelliz y vela,

dijo que era el sabio propio

del encanto de Niquea;

y levantó el buen hidalgo

por hablarle la cabeza.

Mas, viendo que ya le faltan

juicio, vida, vista y lengua,

el escribano se fue

y el cura se salió afuera?

El hidalgo o Cervantes no fueron consecuentes. De haberlo sido, don Quijote bien pudo terminar sus días como lo imaginó Quevedo en su Testamento: loco. En este sentido coinciden Quevedo con Cervantes en la Primera parte. De ahí el acierto, la idea genial de Cervantes al término de la Segunda: el loco recupera el juicio, además se arrepiente y quiere enmendarse. Un final bello y patético que implica un sorpresivo vuelco en la corriente narrativa que venía desarrollándose a través de todo el libro. Por eso Borges expresa que:

Cualquier otro autor hubiera cedido a la tentación de que don Quijote muriera en su ley, combatiendo con gigantes o paladines alucinatorios, reales para él. Almafuerte ha reprochado a Cervantes la lucidez agónica de su héroe. A ello podemos contestar que la forma de la novela exige que don Quijote vuelva a la cordura, y también que este regreso a la cordura es más patético que el morir loco. Es triste que Alonso Quijano vea en la hora de su muerte que su vida entera ha sido un error y un disparate. El sueño de Alonso Quijano cesa con la cordura y también el sueño general del libro, del que pronto despertaremos. Antes que cerremos el volumen y despertemos de ese sueño del arte, don Quijote se nos adelanta despertando él también y volviendo como nosotros a la mera y prosaica realidad ${ }^{8}$.

7 Francisco de Quevedo, Testamento de Don Quijote, Obras completas, ed., introd. y notas de José Manuel Blecua, Planeta, Barcelona, 1963, t. 1, pp. 933-936.

${ }^{8}$ Jorge Luis Borges, "Análisis del último capítulo del Quijote", RUBA, 1956, núm. 1, p. 31. 
Don Quijote ha sido vencido. Acepta resignado cumplir con su promesa de no salir a la aventura por un año y hasta piensa seriamente en hacerse pastor. No obstante, la tristeza, o la melancolía como quiere el texto, lo embarga y muere. Advirtamos que primero muere don Quijote y luego Alonso Quijano el Bueno. En efecto, si leemos con atención el libro, veremos que en el último capítulo don Quijote deja su lugar a don Alonso: "Yo tengo juicio ya, libre y claro", antes sólo "sombras caliginosas de la ignorancia" en lenguaje cervantino; "el sueño de Alonso Quijano cesa con la cordura" en lengua borgeana.

En su poema, Borges evoca el momento preciso de ese inesperado y patético despertar. No se trata de despertar de un sueño de más de seis horas como nos informa el texto, sino también de] fin de un sueño artístico que ha abarcado prácticamente todo e] libro y del amanecer de otro personaje, Alonso Quijano, que lc hace para morir casi de inmediato. El personaje despierta de ur sueño muy especial, que el poeta llama "incierto", porque es in. seguro, no verdadero, tan extraordinario que se acerca a lo des. conocido. Este sueño cae en el campo de lo maravilloso y de $k$ fantástico, por eso, quizá, en vez de decir espada o sable, se dic alfanje, vocablo que nos aleja hacia el mundo oriental tan afír a la fantasía y a la fábula. Sin embargo y de inmediato evoca e "campo llano", la recia meseta castellana, la mancha que se nu tre de viñas y olivares y que, en ocasiones, se convierte en tierr: de pan llevar. El héroe adormilado reacciona como cualquie mortal tocándose la barba, preguntándose por su estado. Los he chiceros de su larga y anterior historia ya no lo persiguen ni 1 hacen daño. Está solo con su conciencia, ha tornado al mund de lo consciente, ha despertado de un largo sueño que lo alejó d la realidad, de su realidad de "hidalgo de lanza en astillerc adarga antigua, rocín flaco y galgo corredor"'. Y ha despertad enfermo, enfermo de melancolía. Para la psiquiatría, se trata d un estado de depresión propio de la psicosis maníaco-depresiva caracterizado por postración, abatimiento y pesimismo. Etimolí gicamente es la negra bilis de los griegos. Para don Alonso Quija no, es más bien esa tristeza un tanto inexplicable, vaga, profur da, producida por ese brusco despertar al mundo de la razór pero que ha calado tan hondo que lo llevará a la muerte.

Este patetismo con que Cervantes trata los últimos, el últirr capítulo del Quijote, se da, en general, más en la Segunda que c la Primera parte. Borges prefiere la Segunda parte; esto no es n vedad ya que varios cervantistas ya lo habían manifestado y $\mathrm{m}$ 
chos lectores de todos los tiempos lo hemos pensado. Con Borges podemos decir:

En esa parte, Cervantes prescinde de esos burdos percances fisicos y todo lo que ocurre es distinto. Es sentimental, es psicológico, ya no hay tantos golpes, ya no hay tantas tundas, ya no hay cosas que eran terribles, graciosas y, al mismo tiempo, novedosas, como la aventura de los molinos. Podríamos decir también, que cuando Cervantes empezó a escribir Don Quijote, él lo conocía muy poco a Alonso Quijano. Quizá eso suceda con todo el libro. Si uno empieza a escribir un libro, uno va compenetrándose con los personajes; en este caso con el personaje Alonso Quijano o don Quijote ${ }^{9}$.

El escritor argentino subraya los diez años que separan la Segunda de la Primera parte, tanto que llega a afirmar que Cervantes en el Quijote de 1605 vio las posibilidades cómicas, en cambio, en el de 1615 vio las posibilidades patéticas. Este padecimiento moral expresado en gustos y actitudes emocionantes surca con mayor o menor profundidad todo el libro, de modo especial el de $1615 \mathrm{y}$, de alguna manera, culmina en el último capítulo. "Es indudable que en estas líneas, Cervantes sintió la muerte de don Quijote como algo propio, como algo muy triste". Ningún lector podrá desmentir esta aseveración. Hay dos vertientes a tener en cuenta: la compenetración del autor con los personajes, fundamentalmente con don Quijote y Sancho, en particular con el protagonista, y la emoción creciente, por momentos patética, que muestra el libro. La muerte de don Quijote es narrada con palabras puntuales y hasta secas: “. . . el cual, entre compasiones y lágrimas de los que allí se hallaron, dio su espíritu, quiero decir que se murió". Borges observa el procedimiento: falta la gran frase literaria, de gran retórica digna del héroe que termina sus días; y, de inmediato, evoca las palabras de Shakespeare a la muerte de Hamlet. La emoción de Cervantes por la muerte del héroe no supera la del amigo. Por eso el final no tolera la posibilidad retórica. Cervantes primero y el lector después quedan simplemente desolados.

La batalla y la metralla de Lepanto fueron un vivo recuerdo desde que el joven veinticuatreno intervino audazmente en esa señalada ocasión. Su recuerdo y su orgullo no eran vanos ni va-

9 Véase Rober to Alifano, Conversando con Borges, Suplemento de la revista Siete Días, 1981, núm. 748, p. 20. 
cía exageración. No miente ni imagina hechizos de libros de caballerías cuando Cervantes, molesto por la aparición del Quijote apócrifo y por las ofensas de su autor, reacciona reflexivamente diciendo que Lepanto es "la más alta ocasión que vieron los siglos pasados, los presentes, ni esperan ver los venideros". Desde su particular punto de vista de hombre y soldado que vivió heroicamente la experiencia, era inimaginable una lid tan grandiosa, ardua y sangrienta como ésa, con toda la carga emotiva que conlleva en aquel preciso momento una victoria sobre el Islam. presidido en la ocasión por los turcos otomanos.

Esa experiencia y esa emoción destilan, por ejemplo, sus pa labras de alabanza al soldado cuando en el "Discurso de las ar mas y las letras" dice así:

Y si este parece pequeño peligro, veamos si le iguala o hac ventajas el de embestirse dos galeras por las proas en mitad del ma espacioso, las cuales enclavijadas y trabadas, no le queda al solda do más espacio del que concede dos pies de tabla del espolón; y con todo esto, viendo que tiene delante de sí tantos ministros d la muerte que le amenazan cuantos cañones de artillería se asesta de la parte contraria, que no distan de su cuerpo una lanza, y vier do que al primer descuido de los pies iría a visitar los profundos st nos de Neptuno, y, con todo esto, con intrépido corazón, llevado c la honra que le incita, se pone a hacer blanco de tanta arcabucerí y procura pasar por tan estrecho paso al bajel contrario... (I, 38

Si nos remitimos a los documentos sobre Lepanto hallareme también dos navíos trabados en fiera lucha que simbolizan de adversarios, dos civilizaciones, a través de sus comandante Uluch Ali y don Juan de Austria. Islámicos y cristianos, fren a frente, dos poderosísimas flotas, luchando por la supremacía $\epsilon$ el Mediterráneo y en el mundo cultural conocido de la época. I batalla empieza en torno a las galeras de los dos jefes supremc que se hallaban reunidos por el espolón, formando una sola pl tea de lucha encarnizada, que muy pronto se generaliza a otr muchas naves. El golfo de Corinto, el estrecho de Lepanto, la b hía de Patras se han incendiado en lo que al principio parec una mañana tranquila de aquel domingo 7 de octubre de 157 El calor de la lucha refleja el ardor de muchos miles de hombı que, con la artillería primero y los arcabuces, luego, terminan la lucha cuerpo a cuerpo. La metralla de las primeras horas $f$ paulatinamente cediendo el lugar a las picas, espadas, alfanj 
lanzas y cuchillos. El coraje de los aliados, en su mayoría españoles, la fe en Dios fomentada por los jefes y bendecida por el mismo papa Pío V, y el poder persuasivo y arrollador de don Juan de Austria logran convertir a esos soldados en nuevos héroes que pelean "en el santo nombre de Dios". Y entre estos héroes hay que señalar al arcabucero Miguel de Cervantes que, aunque enfermo de cuartanas, ocupa audazmente su lugar en el esquife de la "Marquesa", hasta que en el asalto definitivo a la galera capitana enemiga dos arcabuzazos en el pecho y otro en el brazo izquierdo lo detienen. Un ambiente fantástico de leyendas caballerescas. Quijotescas aureolas figuran en las cabezas de héroes temerarios y atrayentes hasta el carisma como don Juan de Austria y Miguel de Cervantes... armadas colosales, mares de sangre, muertos y heridos por doquier... ardua victoria, milagro del "Auxilium Christianorum", la nueva deprecación de la letanía lauretana... orgullo de un hombre que fue soldado, cautivo y escritor, a lo grande.

"El hidalgo fue un sueño de Cervantes / Y don Quijote un sueño del hidalgo", sí, pero también este último sueño reconoce al mismo artífice, al inmortal escritor. Alonso Quijano en el último capítulo y don Quijote a través de casi todo el extenso libro ahora se nos muere, ante el dolor de los circunstantes, del escritor y de nosotros los lectores. Pero se trata de un personaje de una larga historia, no más. No es un hombre de carne y hueso, "sino un sueño de Cervantes, un sueño que pudo haber sido inmortal" 10 . Lo que sucede es que a esta altura de la historia, don Quijote ya no es una ficción, no para el escritor ni para los lectores. El primero, no es extraño, se ha apasionado por el excepcional personaje, y los lectores también. Uno y otros lo sentimos tan cerca, tan realmente hombre que nos parece lo más natural del mundo su mortalidad, debe morir.

Don Quijote no pensó en la larga fábula o ficción, que, de algún modo, debía terminar. No lo pudieron persuadir sus extrañas y hasta fantasmagóricas aventuras, tampoco los azotes, ni las desventuras, ni los "desabrimientos" que incluye el médico en su breve y terminante diagnóstico - hoy diríamos "sinsabores" - sin más. Entonces, Cervantes, tras la derrota ante el Caballero de los Espejos, en las playas barcelonesas, lo vuelve a su aldea manchega y a su casa, e imagina un milagro verosímil, si

${ }^{10}$ Jorge Luis Borges, "Análisis del último capítulo del Quijote”, p. 29. 
lo hay, para los lectores y las creencias populares de aquel tiempo, recobrar el juicio para luego morir:

... y una de las señales por donde conjeturaron se moría fue el haber vuelto con tanta facilidad de loco a cuerdo; porque a las ya dichas razones añadió otras muchas tan bien dichas, tan cristianas y con tanto concierto, que del todo les vino a quitar la duda, y a creer que estaba cuerdo ${ }^{11}$.

Pero más original aún se mostró Cervantes, quien, narrador sagaz, imagina aquel largo sueño en que cae el caballero enfermo, don Quijote, para despertar convertido en Alonso Quijanc el Bueno. De loco a cuerdo, sueño mediante: de don Quijote: mentecato o poco más o menos, a Alonso Quijano, prudente hidalgo. El sueño misterioso e inexplicable ha hecho el señaladc milagro.

De acuerdo: "El hidalgo fue un sueño de Cervantes / Y dor Quijote un sueño del hidalgo. / El doble sueño los confunde y al go..." Quizá la explicación profunda y obvia la haya dado ur docto amigo mío, que concluye un trabajo iluminador sobre ur recurso cervantino, afirmando que "el principal personaje de 1 novela no tiene que serlo el protagonista, sino que puede serl el narrador, como lo es aquí" ". Me atrevo a afirmar que Bor ges estaría de acuerdo. Cervantes, don Quijote, Alonso Quijan el Bueno: sueño y literatura. Abore ad aurem.

Carlos Orlando Nálli: Academia Argentina de Letr: Universidad Nacional de Cus

${ }^{11}$ Hemos dicho que la opinión popular suponía que los locos recobrab el juicio para luego morir. Borges, por su parte, precisa que "una superstici escocesa quiere que los hombres cuerdos que están cerca de la muerte se vu van un poco locos y adquieran virtudes proféticas. Aquí, inversamente, la $\mathrm{c}$ canía de la muerte devuelve la razón a un loco", ibid.

${ }^{12}$ Juan Bautista Avalle-Arce, "Cervantes y el narrador infidente Dicenda, 1988, núm. 7, p. 172. 